\title{
Influência do comportamento do bruxismo de vigília na fadiga dos músculos mastigatórios
}

O bruxismo é caraterizado pela atividade dos músculos mastigatórios durante o sono ou na vigília, indicando uma possível relação entre bruxismo e diferentes sintomas musculares. O presente trabalho teve como objetivo avaliar a influência do comportamento do bruxismo da vigília (BV) na fadiga dos músculos mastigatórios. Para isso, foi recrutada uma amostra de 150 indivíduos saudáveis, de ambos os gêneros com idade entre 22 e 35 anos. A frequência do comportamento de BV foi avaliada em toda a amostra via telefone celular, através da avaliação ecologia momentânea (AEM) por um período de 7 dias. Os indivíduos foram instruídos a relatar em tempo real a condição atual dos músculos da mastigação entre cinco possíveis opções. Posterior à semana de AEM, cada individuo executou um teste de fadiga dos músculos mastigatórios, que consistiu da realização de uma tarefa de apertamento dentário sustentado de $30 \%$ da força máxima de mordida (FMM) pelo maior tempo possível até atingir fadiga. O teste terminou quando o individuo não conseguiu mais produzir a força de mordida na magnitude determinada. A FMM antes e após o teste foram registradas e o tempo foi quantificado. Da mesma forma, foi feita a mensuração do limiar de dor à pressão nos músculos mastigatórios antes e após do teste de fadiga. Foi verificada que a frequência média de pelo menos um comportamento de BV foi de $45,46 \%$, sendo o comportamento "dentes encostando levemente" $(29,38 \%)$ o mais relatado. A fadiga muscular levou a uma redução significativa da força máxima de mordida $(p<0,05)$ e aumento do limiar de dor à pressão na amostra total $(p<0,05)$. Entretanto, o teste de correlação de Spearman mostrou que não houve correlação significativa entre os comportamentos de BV, o grau de fadiga muscular e o limiar de dor à pressão nos músculos mastigatórios. Conclui-se que houve uma frequência relativamente alta de comportamentos de bruxismo de vigília, os quais não parecem impactar o grau de fadiga muscular e o limiar de dor à pressão. Entretanto, a fadiga induzida nos músculos mastigatórios tem potencial para reduzir a força máxima de mordida e aumentar o limiar de dor à pressão.

Palavras-chave: Bruxismo de vigília; Fadiga dos músculos mastigatórios; Avaliação ecológica momentânea. 